\title{
Practical considerations of right lobe living donor liver transplantation in adults
}

\author{
William J Wall MD, Edward Solano MD
}

\begin{abstract}
WJ Wall, E Solano. Practical considerations of right lobe living donor liver transplantation in adults. Can J Gastroenterol 2004;18(Suppl C):12C-18C.
\end{abstract}

The practice of living donor liver transplantation in adults has developed rapidly over the past five years and brings with it a set of unique technical and ethical challenges. The evaluation of potential donors focuses on their health and motives, and the results of noninvasive imaging, with the objective of ensuring the best outcomes for both donors and recipients. Graft volume is critical to success, and venous outflow reconstruction is paramount, although there is no consensus on the preferred method. Biliary tract complications occur in $30 \%$ of recipients. Complications that may interfere with recovery or delay the return to well-being occur in one of every four or five donors. The precise risk of donor death cannot be stated with certainty because comprehensive data on all cases are not available. It is clear, however, that donation of the right lobe of the liver carries with it a much greater risk of mortality than kidney donation. The paucity of details reported on donors who have died make it impossible to determine to what extent the deaths were preventable. The option of living donation is an invitation to expand the criteria for recipient selection to include, for example, patients with tumours that exceed traditional transplant guidelines. The risk-benefit ratios for donors become especially problematic when post-transplant recipient survival is below current standards.

Key Words: Donor issues; Liver transplantation; Living donor; Recipient operation

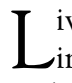
iver transplantation using living donors began 12 years ago $L_{\text {in }}$ response to the critical shortage of donor organs for pediatric recipients (1-4). The concept was an extension of the use of reduced size grafts from deceased donors. Although controversial at the time of its inception $(5,6)$, it gained wide acceptance in a relatively brief period of time. Today, donation of the left lateral segment of the liver from a living adult donor to a child is firmly established in pediatric practice (7). It has helped to significantly reduce the waiting times and mortality for children requiring transplantation.

Living donor liver transplantation (LDLT) in adults has been undertaken during the past five years and, as for children, it was introduced to address the increasing disparity between the supply of donor organs and the number of adult patients awaiting transplantation (8-10). Unlike the pediatric experience, however, controversies surrounding LDLT in adults have continued to escalate since its introduction (11-16). The procedure has ignited much more debate because of the frequency and magnitude of the donor risks associated with removing the right lobe of the liver and its rapid application without

\section{Des considérations pratiques sur la transplan- tation du lobe droit du foie provenant d'un donneur vivant chez des adultes}

La pratique de transplantation du foie provenant d'un donneur vivant chez les adultes a progressé rapidement depuis cinq ans et s'associe à une série de défis techniques et éthiques singuliers. L'évaluation des donneurs potentiels porte sur leur santé et leurs motivations et sur les résultats de l'imagerie non effractive, en vue de garantir la meilleure issue possible à la fois pour les donneurs et pour les transplantés. Le volume de la greffe est essentiel au succès, et la reconstruction du débit veineux est primordiale, même s'il n'existe aucun consensus sur la méthode privilégiée. Des complications des voies biliaires se produisent chez $30 \%$ des transplantés. Des complications qui peuvent nuire à la guérison ou retarder le retour au bien-être s'observent chez un donneur sur quatre ou cinq. Le risque précis de décès des donneurs ne peut être établi avec certitude, car il n'existe pas de données complètes sur tous les cas. Il est toutefois clair que le don du lobe droit du foie comporte un risque de décès beaucoup plus élevé qu'un don de rein. Le peu de détails transmis sur les donneurs décédés empêche de déterminer dans quelle mesure ces décès auraient pu être prévenus. La possibilité de don provenant d'un être vivant constitue une invitation à élargir les critères de sélection des transplantés pour inclure, par exemple, les patients atteints de tumeur habituellement exclus des lignes directrices de transplantation. Les rapports risques-avantages des donneurs deviennent particulièrement problématiques lorsque la survie des transplantés est inférieure aux normes courantes.

comprehensive and detailed donor outcome data. A recent donor death has been widely publicized (17). The present review will consider some practical aspects of LDLT in adults and discuss issues that, in our view, have not been adequately addressed by transplant specialists.

\section{THE LIVING DONOR}

Donor safety is the most important consideration in LDLT. Transplant specialists are obligated to ensure that all circumstances are suitable for the operation to go forward. There is no universally accepted protocol for donor evaluation, but the assessment of potential donors has three objectives: assurance that the donor is physically and mentally healthy; assurance that the motives of the donor are appropriate; and assurance that the donor anatomy and graft size are satisfactory $(18,19)$.

The process should preferably begin with potential donors coming forward spontaneously to express an interest in donation. Information about LDLT can be provided to potential recipients and those close to them at the time of referral for transplantation, but potential donors should not be solicited.

Multi-Organ Transplant Program, London Health Sciences Centre, London, Ontario

Correspondence: Dr William J Wall, Multi-Organ Transplant Program, London Health Sciences Centre, University Campus,

339 Windermere Road, London, Ontario N6H 329. Telephone 519-685-8500 ext 32940, fax 519-663-3067,

e-mail william.wall@lhsc.on.ca 
Donation should be a purely altruistic act, and there should be a demonstrable, significant relationship between the donor and recipient. The initial screening interview, to address the donor's medical history and relationship with the recipient, need not be performed by a physician, nor does it have to be performed at the transplant centre. In many instances, the interview yields information that precludes any further assessment, such as significant health issues or incompatible body size (20).

When screening uncovers no obvious contraindications, a more detailed medical history and physical examination, together with appropriate tests, are undertaken to rule out any unexpected liver disorder or other significant disease $(18,21)$. Any physical condition that could contribute to morbidity after major hepatic resection must be identified. Medical contraindications include morbid obesity, significant cardiovascular disease, respiratory disease, diabetes mellitus or any other major organ dysfunction. Age by itself is not a contraindication. Individuals in their sixth decade have donated (22), but a more intensive investigation should be done to evaluate their surgical risk. Potential donors are advised at the onset of the process that they may halt the assessment at any time. A physician independent of the transplant program is in the best position to provide an impartial assessment and elucidate the motives driving donation. Coercion from family or other sources must be ruled out. If any concerns arise about the donor's motivation or personal relationships, formal psychological or psychiatric evaluation may be required. Potential donors must understand the nature of the operation, the likelihood and nature of adverse events, and what to expect during the recovery period.

Graft size is the most important technical consideration in selecting donors for LDLT. The small-for-size syndrome may result from the implantation of grafts that are too small. Size matching is expressed as either the percentage graft weight to recipient body weight or the percentage of graft volume to standard liver volume (23). A percentage graft weight to recipient body weight between $0.8 \%$ and $1.0 \%$ or a percentage of graft volume to standard liver volume of $40 \%$ or more is considered to be adequate $(20,24)$. The lower limits are not absolute, as shown by documented successes with grafts below the commonly accepted ratios (25-27). Nevertheless, caution should be exercised with the use of small grafts, and they should be avoided for recipients with severe hepatic decompensation or severe portal hypertension $(19,28)$. The sickest recipients need large grafts, not small ones.

If steatosis is present, donor graft size needs to be corrected for fat content. It has been suggested that every $1 \%$ of steatosis decreases functional graft mass by $1 \%$ (19). Thus, the percent fat content should be subtracted to calculate true graft size. The acceptable limit of steatosis has not been determined for donation, but there are reported cases in which grafts with up to $30 \%$ fat have been used successfully.

The incidence of steatosis in the donor liver has some correlation with the body mass index (BMI). In the study by Rinella et al (29), no patient with a BMI of $25 \mathrm{~kg} / \mathrm{m}^{2}$ or lower had steatosis, a BMI of $25 \mathrm{~kg} / \mathrm{m}^{2}$ to $28 \mathrm{~kg} / \mathrm{m}^{2}$ was associated with a $33 \%$ incidence of steatosis, and a BMI greater than $28 \mathrm{~kg} / \mathrm{m}^{2}$ was associated with a $76 \%$ incidence of steatosis. Computed tomography (CT) and magnetic resonance imaging (MRI) are useful in detecting steatosis, but may not accurately quantify the percentage of fat. Most centres use percutaneous liver biopsy selectively; for example, in potential donors whose imaging suggests the presence of steatosis or for those with a BMI over a certain value. A different view has been put forward by Ryan et al (30), who suggested that all donors should undergo biopsy. In their series of liver biopsies in 100 consecutive living donors, BMI correlated very weakly with histological estimates of fat content. The majority $(73 \%)$ of those with a BMI greater than $25 \mathrm{~kg} / \mathrm{m}^{2}$ had no histological evidence of steatosis, while $9 \%$ of those with a BMI below $25 \mathrm{~kg} / \mathrm{m}^{2}$ had at least $10 \%$ steatosis. In addition, the biopsies detected occult liver disease in three potential donors. The risk associated with a liver biopsy is very small, but it is not negligible, and must be balanced against the chance of finding occult disease and potentially sparing the donor an unnecessary operation.

The radiological expertise and equipment at any given centre will influence what preoperative imaging is used to define the hepatobiliary anatomy (31-33). With the accuracy of high resolution CT angiography, MR angiography and Doppler ultrasonography, the trend is to use minimally invasive imaging, which improves donor convenience and safety. Venous and arterial anatomy can usually be visualized noninvasively $(34,35)$, although angiography is used routinely in some centres (9). CT with three-dimensional reconstruction has been shown to be highly accurate in defining venous anatomy and moderately helpful in defining arterial anatomy (32). Abnormal anatomy does not necessarily preclude donation, but documentation is valuable for planning surgery. Unfavourable biliary anatomy, such as a left or right lobe duct draining into the opposite side, can be documented preoperatively by endoscopic retrograde cholangiopancreatography, multidetector CT cholangiography or MR cholangiopancreatography. Assessment of the biliary tree with MR cholangiopancreatography (36) or multidetector CT cholangiography (37) correlates well with intraoperative cholangiography. Given the accuracy of MRI in assessing the hepatic parenchyma, vascular anatomy and the biliary system, it can provide a comprehensive preoperative assessment (38).

\section{RECIPIENT SELECTION}

When LDLT was introduced, it was intended to provide transplants for candidates waiting for grafts from deceased donors. Initially, good-risk recipients were selected, which reserved livers from deceased donors for sicker, more urgent recipients and made it easier to justify donor risks for recipients who would have the very best survival after transplantation. It also allowed ample time for donor assessment and thoughtful discussion before obtaining consent. There is tremendous logic in this approach. It is also sensible to specifically apply LDLT to patients on the list for a deceased donor graft who are disadvantaged by the fact that they are assigned a relatively low priority despite being in need of transplantation. They include patients with cholestatic and metabolic liver diseases, and those with a deteriorating quality of life due, for example, to disabling fatigue, pruritus or encephalopathy. LDLT can provide transplantation for them at the most opportune stage of their illnesses. The same considerations apply to patients with early hepatocellular carcinoma. The provision of LDLT to these recipients at the ideal time should reduce their attrition rate due to tumour progression (39).

The view that LDLT should be restricted to only the bestrisk recipients is probably too narrow. Lo et al (8) have argued that donor risk is best justified when a very sick patient needs 
an urgent transplant. Certainly, LDLT can save the lives of patients with fulminant hepatic failure (40-42) and critically ill patients with decompensated liver disease (43). Although they are prioritized on the waiting list, they deteriorate quickly, and organs from deceased donors may not become available in a timely fashion. Living donor assessment can be accomplished in a matter of hours in specific situations, and the timing of transplantation can be optimized if a living donor comes forward early enough. Whether LDLT would result in higher patient and graft survival after transplantation in patients with fulminant hepatic failure than with cadaveric grafting is not yet known. When LDLT is used for desperately ill patients with chronic liver disease, recipient survival rates of $43 \%$ have been reported (43). Because the one-year mortality rate of $57 \%$ after LDLT far exceeds the $18 \%$ rate after cadaveric transplantation for United Network for Organ Sharing status 2A recipients, the appropriateness of using living donors in these circumstances has been questioned (44).

There has been spirited discussion at transplant meetings concerning the use of living donors to provide transplants for patients who would not otherwise qualify for the procedure, especially those with malignancies that are advanced beyond currently accepted guidelines. Historical reports show that some of these patients can enjoy extended survival and occasionally be cured $(45,46)$, but the shortage of organs from deceased donors currently denies these patients access to transplantation. In some centres, LDLT is seen as a solution for cancer victims who would not otherwise receive transplants. Gondolesi et al (47) reported that more than one-half of the cancers treated with LDLT were greater than $8 \mathrm{~cm}$ in diameter. Donors will sometimes come forward for these patients, even if they understand that the chance of curing the recipient is slim. The question is how low of a recipient cure rate is acceptable to risk the life of a healthy living donor. Under the urging of family members, LDLT is also contemplated for other patients with severe alcoholic liver disease who do not satisfy abstinence criteria or for those with recurrent hepatitis $\mathrm{C}$. These scenarios are becoming more frequent occurrences, and ethical debates about recipient rights to treatment and donor autonomy can be expected to dominate the discussions.

\section{TECHNICAL ASPECTS OF DONOR AND RECIPIENT OPERATIONS}

The many technical varieties of LDLT in adults reflect the evolving nature of these unique donor and recipient operations. Right lobe grafts are preferred in most centres, having the advantages of size and easier anatomical reconstruction. Left lobe grafts are still popular in East Asia, but extended right lobe grafts (segments 4 to 8 ) are widely regarded as too extensive for the donor.

\section{The donor operation}

It is useful to mark the intended site of division of the bile duct to the right lobe with a radiopaque clip and correlate it with the operative cholangiogram. Dissection of the right branch of the hepatic artery is undertaken to the right of the common bile duct, with minimal disruption to the hepatic parenchyma surrounding the biliary branches to the right lobe to reduce the risk of ductal ischemia (48). Occasionally, the portal vein trifurcates into right anterior, right posterior and left branches.
Dual branches to the right lobe are taken separately, leaving the afferent venous supply to the donor left lobe intact.

When the right lobe is separated from the inferior vena cava (IVC), sizable (greater than $5 \mathrm{~mm}$ ) venous branches and true accessory right hepatic veins are preserved. In most cases, the right hepatic vein is large and is the only draining vein required for a right lobe graft. In up to $24 \%$ of individuals, however, the right hepatic vein is relatively small and an inferior or accessory right hepatic vein, or a tributary from the middle hepatic vein, also provides significant drainage of the right lobe (49). Accessory veins should be preserved and reimplanted into the recipient liver to avoid venous congestion of the graft or even graft failure $(31,49)$. The plane of hepatic transection is determined primarily by the course of the middle hepatic vein, which should be identified by intraoperative ultrasonography $(31,33,49,50)$. The middle hepatic vein drains segment 4 , but it may also drain significant parts of segments 5 and 8 , as well as variable areas of segments 2 and 3 . Some surgeons recommend division of the liver to the left of the middle hepatic vein, thereby including it with the graft to ensure adequate venous drainage (8,50-52). Others recommend that the division be performed to the right of the middle hepatic vein, arguing that the drainage of the middle hepatic vein is not always significant and that taking it risks injury to the left hepatic vein and, potentially, leaves an inadequate mass of liver in the donor $(49,53,54)$. Obviously, either approach can be used (55). If division to the right of the middle hepatic vein is selected, significant tributaries draining segments 5 and 8 should be preserved for reimplantation, using vein grafts if necessary $(31,33,49,53-58)$.

The bile duct is transected after enough hepatic parenchyma has been divided to permit good visualization. Sharp dissection is used and tissue is purposely left around the bile duct orifice. In nearly $40 \%$ of cases, there is more than one duct draining the right lobe, but a ductoplasty may allow the creation of a single orifice for anastomosis in the recipient (33). The use of tissue sealants on the cut edge of the liver should not replace meticulous efforts to secure each vascular and biliary tributary with hemoclips or ligatures.

\section{The recipient operation}

Marcos et al (59) have detailed the critical inter-relationships between graft volume, venous outflow and inflow, and their importance to optimize graft function and avoid venous congestion. Right lobe grafts are immediately subjected to substantial increases in portal perfusion after engraftment. Thus, it is imperative that the venous outflow of the graft is technically perfect. When the venous outflow is constructed, total occlusion of the IVC allows maximal caval manipulation to facilitate the creation of a wide anastomosis. We prefer to construct an anastomosis that uses the orifice of the recipient right hepatic vein, often enlarging it vertically on the IVC, as has been described by several authorities $(53,59)$. Significant accessory hepatic veins are separately anastomosed to the IVC directly, or with vein grafts or remnants of the recipient middle hepatic vein (54). The donor right portal vein is anastomosed to either the recipient right or main portal vein, depending on length and calibre. Two portal vein donor branches can be managed with various techniques. If they are in close proximity, a single lumen venoplasty may be possible to allow one anastomosis to the recipient's vein (31). Alternatively, the two donor branches can be anastomosed separately to the recipient right and left 
portal vein, either in situ or using backtable reconstruction with a Y-graft of the recipient portal vein bifurcation (60). Venous flow can be assessed intraoperatively after reperfusion using Doppler ultrasound $(58,61)$.

Hepatic arterial reconstruction is usually end-to-end to the recipient hepatic artery proper or its right branch. A jump graft using the saphenous vein overcomes inadequate length. Microvascular techniques may be used, but are not always necessary (31). Occasionally, two hepatic arteries supply the right lobe graft. A suggested technique to deal with this anomaly is backtable reconstruction with a Y-graft consisting of the bifurcation of the recipient's right and left hepatic arteries taken to the level of the gastroduodenal artery takeoff (60).

A single biliary anastomosis is associated with a lower biliary complication rate (62). Fan et al (63) have recently emphasized the importance of proper technique to avoid biliary problems. By precise location of the division of the right hepatic duct, they have obtained a single orifice in most of their cases. Also, they made an effort to create one orifice by ductoplasty and stressed the importance of creating a jejunal opening equal in size to the right hepatic duct. The application of these principles reduced their biliary complication rate from $43 \%$ to $8 \%$. A Roux-en-Y hepaticojejunostomy is still our preference, but duct-to-duct reconstructions are often used $(53,63,64)$. A role has been suggested for biliary stents $(31,33,63)$, but, as with whole organ transplants, there are no firm data to show that they reduce the incidence of biliary complications.

\section{POSTOPERATIVE COMPLICATIONS}

\section{Donor outcome}

Few analyses have been published that provide comprehensive details about donor outcomes after right hepatic lobectomy. Many reports $(65,66)$ include major, but not minor, complications, and few include pertinent information on the length of stay, readmission rates (and reasons), time before returning to work, quality of life after donation and long-term health. From the available information, however, it is clear that the risks of a right hepatic lobectomy in a healthy donor are significant and that there is considerable postoperative morbidity $(22,54,65,67-70)$. Approximately $20 \%$ to $25 \%$ of donors experience an adverse event or symptom that may or may not interfere with their recovery. A survey of 42 transplant centres in the United States obtained data on 433 adult LDLT procedures (66). Thirteen centres accounted for $80 \%$ of the transplants. Biliary complications requiring intervention occurred in $16 \%$ of the donors, and $5 \%$ required reoperation. The overall complication rate was $21 \%$, and $10 \%$ of donors had to be readmitted to hospital (71). Complication rates tended to be lower in high volume centres, but the differences were not statistically significant.

Beavers et al (69) analyzed complications involving 409 right lobe donors from 12 series in the literature (six North American, four Asian and two European) and estimated that the crude morbidity rate was $31 \%$. The most frequent complications were bile leaks, prolonged ileus and minor wound problems, followed by pleural effusions, atelectasis and neurapraxia. Readmission rates were infrequently reported but some were as high as $22 \%$. Time to recovery, in the two series that reported it, averaged three to four months, similar to that recently reported in a Berlin study (22). A survey of 1508 living liver donors in five Asian centres showed that right lobe donors had the highest complication rate $(28 \%)$, and their complications were more serious than left lobe or left lateral segment donors (70).
There are significant quality-of-life issues affecting donors. In an analysis by Trotter et al (72), 71\% of right lobe donors reported ongoing symptoms, including $42 \%$ with a change in body image, and almost one-third had sought medical attention. When donors are carefully followed, it is evident that they feel unwell for a long time afterwards. Nevertheless, donors generally indicate that they were happy that they donated and would make the same decision again (72).

Although donor mortality cannot be accurately quantified because of incomplete data, it is certain that more deaths have occurred than have been reported in medical journals. A total of seven donor deaths have been mentioned in reports from transplant centres. The first was a parental donor for a child in Germany, a 29-year-old mother who died of a pulmonary embolus two days after surgery (73). She was overweight, smoked and was taking contraceptives (74). There have been six more deaths reported in right or extended right lobe donors $(66,69,75-78)$, and it is claimed that there have been others $(11,16)$. It is relevant to compare the risk of right lobe donor mortality with living kidney donation, which is approximately three per 10,000 donors $(79,80)$. At the time of writing the present review, there had been approximately 1500 right lobe donors. Thus, the mortality rate for living right lobe donation is obviously much greater than it is for kidney donation.

\section{Recipient outcome}

The survival of LDLT recipients is good, but technical complications are greater than with whole-size grafts. The incidence of biliary complications ranges from $15 \%$ to $64 \%$ $(10,54,62)$, which is significantly higher than the $10 \%$ to $15 \%$ rate after whole-sized transplantation $(81,82)$. Leakage of bile from the anastomosis or from the cut edge is common. Although most leaks can be managed nonoperatively, they prolong hospital stay and consume resources. Biliary strictures can result from very small bile ducts, the sequelae of bile leaks or ischemic injury. Occasionally, stenting may be all that is required, but operative intervention is often needed. Because of the greater concern for vascular patency and adequacy of blood flow with LDLT than with whole organ grafts, postoperative monitoring with Doppler ultrasound has become routine. Lower doses of tacrolimus are required after LDLT to achieve therapeutic blood levels $(83,84)$.

Concerns have been raised about the vulnerability of living donor grafts to reinfection with hepatitis C. A few reports $(85,86)$ have suggested that partial grafts from living donors are more prone to aggressive, recurrent hepatitis $\mathrm{C}$ than are whole grafts from deceased donors. It has been postulated that hepatic regeneration enhances hepatocyte infection with the virus, although other mechanisms may also be operative, such as genetic homology of donor-recipient pairs (87). Russo et al (88) recently analyzed United Network for Organ Sharing data on 279 LDLT hepatitis C-positive recipients and found that oneand two-year patient and graft survival were not significantly different from 3995 hepatitis C-positive recipients who received deceased donor grafts. As pointed out by the authors, and emphasized in a slightly different way in an accompanying editorial (89), differences in the severity of illness pretransplant need to be considered when interpreting survival after transplantation. Recipients of living donor grafts are, as a group, less sick. In addition, other variables that may impact the development of recurrent hepatitis $\mathrm{C}$ (eg, viral load, genotype, type of 
immunosuppression and treated rejection) need to be taken into account. Longer follow-up and more comprehensive data are needed before this issue can be clarified.

\section{UNRESOLVED ISSUES}

The major issue facing LDLT today is the lack of information on donor mortality and, to a lesser extent, morbidity. Hepatologists and surgeons have an obligation to provide potential donors and recipients with accurate information about risks and outcomes, otherwise, informed consent is impossible. The fact that donors are prepared to accept very high risks does not lessen that obligation. The lack of agreement on the real risk of mortality was revealed in a survey (66) of 42 adult-to-adult living donor programs in the United States. When asked what death rate was quoted to potential donors, the answers varied from less than one in 1000 to more than one in 100 (66). Surely, the estimate of mortality given to potential liver donors should not vary in logarithmic proportions. This is a pressing issue, especially when expanded criteria for recipient selection are currently being put forward and donor risks are being balanced against recipient survival rates that may be much lower than the $80 \%$ to $85 \%$ success rate we have come to expect.

The picture that is emerging of the morbidity of right lobe donation is not comforting. Donors need to understand that complications and persistent symptoms frequently occur, and that recovery is prolonged. Data sets on donor morbidity are still far from complete. Publications that address donor complications should report all complications and their impact on ultimate recovery, including hospitalization, readmission and time to return to work. Moreover, the reasons for persistent symptoms are poorly understood. Some donor operations have been aborted, but only one centre has provided any information on this issue (54). Unless these unfortunate cases are detailed in the literature, the transplant community will not learn from the experience of others. Some donors have had to be rescued by liver transplants themselves, but details of these cases have not been reported in any manner that would be instructive to others (66).

\section{REFERENCES}

1. Raia S, Nery JR, Mies S. Liver transplantation from live donors. Lancet 1989;2:497.

2. Strong RW, Lynch SV, Ong TH, Matsunami H, Koido Y, Balderson GA. Successful liver transplantation from a living donor to her son. N Engl J Med 1990;322:1505-7.

3. Broelsch CE, Whitington PF, Emond JC, et al. Liver transplantation in children from living related donors. Surgical techniques and results. Ann Surg 1991;214:428-39.

4. Tanaka K, Uemoto S, Tokunaga Y, et al. Surgical techniques and innovations in living related liver transplantation. Ann Surg 1993;217:82-91.

5. Singer PA, Siegler M, Whitington PF, et al. Ethics of liver transplantation with living donors. N Engl J Med 1989;321:620-2.

6. Busuttil RW. Living-related liver donation: CON. Transplant Proc 1991;23:43-5.

7. Amersi F, Farmer DG, Busuttil RW. Fifteen-year experience with adult and pediatric liver transplantation at the University of California, Los Angeles. Clin Transpl 1998:255-61.

8. Lo CM, Fan ST, Liu CL, et al. Adult-to-adult living donor liver transplantation using extended right lobe grafts. Ann Surg 1997;226:261-70.

9. Wachs ME, Bak TE, Karrer FM, et al. Adult living donor liver transplantation using a right hepatic lobe. Transplantation 1998;66:1313-6.

10. Marcos A, Ham JM, Fisher RA, Olzinski AT, Posner MP. Single-center analysis of the first 40 adult-to-adult living donor
There is inadequate reporting of the numbers and the circumstances of donor deaths. Mortality is greater than has been documented in medical journals. The descriptions in the literature of fatal outcomes after right lobe donation provide little insight into cause or prevention. One was from "sepsis" (69), one from "an unclear cause" (76) and one from "liver insufficiency because of a previously unrecognized congenital lipodystrophy of the liver" (75). The paucity of information does not allow us to determine if the deaths could have been prevented or what factors may have contributed to them. Postmortem findings have not been reported. The lack of detailed information on donor mortality contrasts sharply with the painstaking documentation by Starzl and colleagues (90) of the "difficulties and tragedies" of liver transplantation more than three decades ago $(91,92)$. Those descriptions and what was learned from them provided the foundation on which all subsequent liver transplantation was built. It would be regrettable if information on perioperative donor mortality was not gathered and analyzed in a similar fashion, so that transplant specialists could use it for the benefit of future donors. Detailed data on all existing donor deaths (including preoperative investigations, operative details, postoperative courses and autopsy findings) should be shared to allow meaningful interpretation. Only that kind of analysis will permit objective determination of how best to avoid future tragedies. The National Institutes of Health and The American Society of Transplant Surgeons recently announced a prospective study of adult LDLT at ten centres in the United States. The purpose is to gather accurate data on their risks and benefits, but the seven-year analysis will not provide timely answers to questions that need immediate attention.

It is unsettling that the transplant community cannot state the current mortality rate for right lobe liver donation. It is not as low as one in 1000 , but whether it is one in 500 , one in 200 or closer to one in 100 is a matter of speculation. It is irrational to think that surgery of this magnitude could be performed repeatedly on a large scale with negligible mortality. Until the true risk is known, informed consent is problematic.

liver transplants using the right lobe. Liver Transpl 2000;6:296-301.

11. Strong RW. Whither living donor liver transplantation? Liver Transpl Surg 1999;5:536-8.

12. Caplan AL. Proceed with caution: Live living donation of lobes of liver for transplantation. Liver Transpl 2001;7:494-5.

13. Shaw BW Jr. Where monsters hide. Liver Transpl 2001;7:928-32.

14. Cronin DC 2nd, Millis JM, Siegler M. Transplantation of liver grafts from living donors into adults - too much, too soon. N Engl J Med 2001;344:1633-7.

15. Busuttil RW. How safe are donors in adult-to-adult living related liver transplantation? Liver Transpl 2002;8:121-2.

16. Surman OS. The ethics of partial-liver donation. N Engl J Med 2002;346:1038

17. Gorman C. The ultimate sacrifice. Time 2002;159:41.

18. Trotter JF. Selection of donors and recipients for living donor liver transplantation. Liver Transpl 2000;6(Suppl 2):S52-8.

19. Marcos A, Fisher RA, Ham JM, et al. Selection and outcome of living donors for adult to adult right lobe transplantation. Transplantation 2000;69:2410-5.

20. Trotter JF, Wachs M, Trouillot T, et al. Evaluation of 100 patients for living donor liver transplantation. Liver Transpl 2000;6:290-5.

21. Trotter JF, Wachs M, Everson GT, Kam I. Adult-to-adult transplantation of the right hepatic lobe from a living donor. N Engl J Med 2002;346:1074-82. 
22. Pascher A, Sauer IM, Walter M, et al. Donor evaluations, donor risks, donor outcome and donor quality of life in adult-to-adult living donor liver transplantation. Liver Transpl 2002;8:829-37.

23. Sugawara Y, Makuuchi M, Takayama T, Imamura H, Kaneko J, Ohkubo T. Safe donor hepatectomy for living related liver transplantation. Liver Transpl 2002;8:58-62.

24. Sugawara Y, Makuuchi M, Takayama T, et al. Small-for-size grafts in living-related liver transplantation. J Am Coll Surg 2001;192:510-3.

25. Kiuchi T, Kasahara M, Uryuhara K, et al. Impact of graft size mismatching on graft prognosis in liver transplantation from living donors. Transplantation 1999;67:321-7.

26. Nishizaki T, Ikegami T, Hiroshige S, et al. Small graft for living donor liver transplantation. Ann Surg 2001;233:575-80.

27. Kiuchi T, Tanaka K, Ito T, et al. Small-for-size grafts in living donor liver transplantation: How far should we go? Liver Transpl 2003;9:S29-35.

28. Ben-Haim M, Emre S, Fishbein TM, et al. Critical graft size in adult-to-adult living donor liver transplantation: Impact of the recipient's disease. Liver Transpl 2001;7:948-53.

29. Rinella ME, Alonso E, Rao S, et al. Body mass index as a predictor of hepatic steatosis in living liver donors. Liver Transpl 2001;7:409-14.

30. Ryan CK, Johnson LA, Germin BI, Marcos A. One hundred consecutive hepatic biopsies in the workup of living donors for right lobe liver transplantation. Liver Transpl 2002;8:1114-22.

31. Marcos A, Ham JM, Fisher RA, Olzinski AT, Posner MP. Surgical management of anatomical variations of the right lobe in living donor liver transplantation. Ann Surg 2000;231:824-31.

32. Bogetti JD, Herts BR, Sands MJ, Carroll JF, Vogt DP, Henderson JM. Accuracy and utility of 3-dimensional computed tomography in evaluating donors for adult living related liver transplants. Liver Transpl 2001;7:687-92.

33. Nakamura T, Tanaka K, Kiuchi T, et al. Anatomical variations and surgical strategies in right lobe living donor liver transplantation: Lessons from 120 cases. Transplantation 2002;73:1896-903.

34. Bassignani MJ, Fulcher AS, Szucs RA, Chong WK, Prasad UR, Marcos A. Use of imaging for living donor liver transplantation. Radiographics 2001;21:39-52.

35. Kamel IR, Kruskal JB, Pomfret EA, Keogan MT, Warmbrand G, Raptopoulos V. Impact of multidetector CT on donor selection and surgical planning before living adult right lobe liver transplantation. Am J Roentgenol 2001;176:193-200.

36. Cheng YF, Chen CL, Huang TL, et al. Single imaging modality evaluation of living donors in liver transplantation: Magnetic resonance imaging. Transplantation 2001;72:1527-33.

37. Schroeder T, Malago M, Debatin JF, et al. Multidetector computed tomographic cholangiography in the evaluation of potential living liver donors. Transplantation 2002;73:1972-3.

38. Goyen M, Barkhausen J, Debatin JF, et al. Right-lobe living related liver transplantation: Evaluation of a comprehensive magnetic resonance imaging protocol for assessing potential donors. Liver Transpl 2002;8:241-50.

39. Sarasin FP, Majno PE, Llovet JM, Bruix J, Mentha G, Hadengue A. Living donor liver transplantation for early hepatocellular carcinoma: A life-expectancy and cost-effectiveness perspective. Hepatology 2001;33:1073-9.

40. Kato T, Nery JR, Morcos JJ, et al. Successful living related liver transplantation in an adult with fulminant hepatic failure. Transplantation 1997;64:415-7.

41. Uemoto S, Inomata Y, Sakurai T, et al. Living donor liver transplantation for fulminant hepatic failure. Transplantation 2000;70:152-7.

42. Marcos A, Ham JM, Fisher RA, et al. Emergency adult to adult living donor liver transplantation for fulminant hepatic failure. Transplantation 2000;69:2202-5.

43. Testa G, Malago M, Nadalin S, et al. Right-liver living donor transplantation for decompensated end-stage liver disease. Liver Transpl 2002;8:340-6.

44. Kam I. Adult-to-adult right hepatic lobe living donor liver transplantation for status 2a patients: Too little, too late. Liver Transpl 2002;8:347-9.

45. McPeake JR, O'Grady JG, Zaman S, et al. Liver transplantation for primary hepatocellular carcinoma: Tumor size and number determine outcome. J Hepatol 1993;18:226-34.
46. Pichlmayr R, Weimann A, Oldhafer KJ, et al. Role of liver transplantation in the treatment of unresectable liver cancer. World J Surg 1995;19:807-13.

47. Gondolesi G, Munoz L, Matsumoto C, et al. Hepatocellular carcinoma: A prime indication for living donor liver transplantation. J Gastrointest Surg 2002;6:102-7.

48. Renz JF, Reichert PR, Emond JC. Hepatic arterial anatomy as applied to living-donor and split-liver transplantation. Liver Transpl 2000;6:367-9.

49. Ghobrial RM, Hsieh CB, Lerner S, et al. Technical challenges of hepatic venous outflow reconstruction in right lobe adult living donor liver transplantation. Liver Transpl 2001;7:551-5.

50. Fan ST, Lo CM, Liu CL. Technical refinement in adult-to-adult living donor liver transplantation using right lobe graft. Ann Surg 2000;231:126-31.

51. Fan S-T, Lo CM, Liu CL, Wang WX, Wong J. Safety and necessity of including the middle hepatic vein in the right lobe graft in adultto-adult live donor liver transplantation. Ann Surg 2003;238:137-48.

52. Scatton O, Belghiti J, Dondero F, et al. Harvesting the middle hepatic vein with a right hepatectomy does not increase the risk for the donor. Liver Transpl 2004;10:71-6

53. Grewal HP, Shokouh-Amiri MH, Vera S, Stratta R, Bagous W, Gaber AO. Surgical technique for right lobe adult living donor liver transplantation without venovenous bypass or portocaval shunting and with duct-to-duct biliary reconstruction. Ann Surg 2001;233:502-8.

54. Miller CM. Gondolesi GE, Florman S, et al. One hundred nine living donor liver transplants in adults and children: A singlecenter experience. Ann Surg 2001;234:301-12.

55. DeVilla VH, Chen C-L, Chen Y-S, et al. Right lobe living donor liver transplantation - addressing the middle hepatic vein controversy. Ann Surg 2003;238:275-82.

56. Marcos A, Fisher RA, Ham JM, et al. Right lobe living donor liver transplantation. Transplantation 1999;68:798-803.

57. Sugawara Y, Makuuchi M, Imamura H, Kaneko J, Ohkubo T, Kokudo N. Outflow reconstruction in recipients of right liver graft from living donors. Liver Transpl 2002;8:167-8.

58. Gondolesi GE, Florman S, Matsumoto C, et al. Venous hemodynamics in living donor right lobe liver transplantation. Liver Transpl 2002;8:809-13.

59. Marcos A, Orloff M, Mieles L, Olzinski AT, Renz JF, Sitzmann JV. Functional venous anatomy for right-lobe grafting and techniques to optimize flow. Liver Transpl 2001;7:845-52.

60. Marcos A, Orloff M, Mieles L, Olzinski A, Sitzmann J. Reconstruction of double hepatic arterial and portal venous branches for right-lobe living donor liver transplantation. Liver Transpl 2001;7:673-9.

61. Shapiro RS, Fishbein T, Schwartz M, Miller CM. Use of intraoperative Doppler ultrasound to diagnose hepatic venous obstruction in a right lobe living donor liver transplant. Liver Transpl 2001;7:547-50.

62. Testa G, Malago M, Valentin-Gamazo C, Lindell G, Broelsch CE. Biliary anastomosis in living related liver transplantation using the right liver lobe: Techniques and complications. Liver Transpl 2000;6:710-4

63. Fan ST, Lo CM, Liu CL, Tso WK, Wong J. Biliary reconstruction and complications of right lobe live donor liver transplantation. Ann Surg 2002;236:676-83.

64. Ishiko T, Egawa H, Kasahara M, et al. Duct-to-duct biliary reconstruction in living donor liver transplantation utilizing right lobe graft. Ann Surg 2002;236:235-40.

65. Beavers KL, Sandler RS, Shrestha R. Donor morbidity associated with right lobectomy for living donor liver transplantation to adult recipients: A systematic review. Liver Transpl 2002;8:110-7.

66. Brown RS, Russo MW, Lai M, et al. A survey of liver transplantation from living adult donors in the United States. N Engl J Med 2003:348:818-25.

67. Fan ST, Lo CM, Liu CL, Yong BH, Chan JK, Ng IO. Safety of donors in live donor liver transplantation using right lobe grafts. Arch Surg 2000;135:336-40.

68. Pomfret EA, Pomposelli JJ, Lewis WD, et al. Live donor adult liver transplantation using right lobe grafts: Donor evaluation and surgical outcome. Arch Surg 2001;136:425-33.

69. Beavers KL, Sandler RS, Fair JH, Johnson MW, Shrestha R. The living donor experience: Donor health assessment and outcomes after living donor liver transplantation. Liver Transpl 2001;7:943-7. 
70. Lo CM. Complications and long-term outcome of living liver donors: A survey of 1508 cases in five Asian centers. Transplantation 2003;75(3 Suppl):S12-5.

71. Shiffman ML, Brown RS Jr, Olthoff KM, et al. Living donor liver transplantation: Summary of a conference at The National Institutes of Health. Liver Transpl 2002;8:174-88.

72. Trotter JF, Talamantes M, McClure M, et al. Right hepatic lobe donation for living donor liver transplantation: Impact on donor quality of life. Liver Transpl 2001;7:485-93.

73. Malago M, Rogiers X, Burdelski M, Broelsch C. Living related liver transplantation: 36 cases at the University of Hamburg. Transplant Proc 1994;26:3620-1.

74. Sterneck MR, Fischer L, Nischwitz U, et al. Selection of the living liver donor. Transplantation 1995;60:667-71.

75. Malago M, Testa G, Frilling A, et al. Right living donor liver transplantation: An option for adult patients. Ann Surg 2003;238:853-70.

76. Boillot O, Dawahra I, Mechet I, et al. Liver transplantation using a right liver lobe from a living donor. Transplant Proc 2002;34:773-6.

77. Florman S, Miller CM. Living donor liver transplantation in adults. Curr Opin Organ Transplant 2003;8:131-8.

78. Akabayashi A, Slingsby B, Fujita M. The first donor death after living-related liver transplantation in Japan. Transplantation 2004;77:634.

79. Najarian JS, Chavers BM, McHugh LE, Matas AJ. 20 years or more of follow-up of living kidney donors. Lancet 1992;340:807-10.

80. Johnston EM, Remucal MJ, Gillingham KJ, Dahms RA, Najarian JS, Matas AJ. Complications and risks of living donor nephrectomy. Transplantation 1997;64:1124-8.

81. Greif F, Bronsther OL, van Thiel DH, et al. The incidence, timing, and management of biliary tract complications after orthotopic liver transplantation. Ann Surg 1994;219:40-5.
82. Verran DJ, Asfar SK, Ghent CN, Grant DR, Wall WJ. Biliary reconstruction without $\mathrm{T}$ tubes or stents in liver transplantation: Report of 502 consecutive cases. Liver Transpl Surg 1997;3:365-73.

83. Trotter JF, Stolpman N, Wachs M, et al. Living donor liver transplant recipients achieve relatively higher immunosuppressant blood levels than cadaveric recipients. Liver Transpl 2002;8:212-8.

84. Taber DJ, Dupuis RE, Fann AL, et al. Tacrolimus dosing requirements and concentrations in adult living donor liver transplant recipients. Liver Transpl 2002;8:219-23.

85. Troppman C, Rossaro L, Perez RV, McVicar JP. Early, rapidly progressive cholestatic hepatitis $\mathrm{C}$ reinfection and graft loss after adult living donor liver transplantation. Amer J Transplant 2003;3:239-40.

86. Gaglio PJ, Malireddy S, Levitt BS, et al. Increased risk of cholestatic hepatitis $\mathrm{C}$ in recipients of grafts from living versus cadaveric liver donors. Liver Transpl 2003;9:1028-35.

87. Baltz AC, Trotter JF. Living donor liver transplantation and hepatitis C. Clin Liver Dis 2003;7:651-65.

88. Russo MW, Galanko, J, Beavers K, Fried MW, Shrestha R. Patient and graft survival in hepatitis $\mathrm{C}$ recipients after adult living donor liver transplantation in the United States. Liver Transpl 2004;10:340-6.

89. Forman LM, Trotter JF, Edmond J. Living donor liver transplantation and hepatitis C. Liver Transpl 2004;10:347-8.

90. Starzl TE. Experience in Hepatic Transplantation. Philadelphia: WB Saunders Company, 1969:xi.

91. Starzl TE, Marchioso TL, von Kaulla K, Herman GG, Brittain RS, Waddell WR. Homotransplantation of the liver in humans. Surg Gynecol Obstet 1963;117:659-76.

92. Starzl TE, Groth CG, Brettschneider L, et al. Orthotopic homotransplantation of the human liver. Ann Surg $1968 ; 168: 392-415$. 


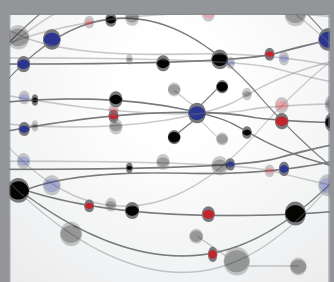

The Scientific World Journal
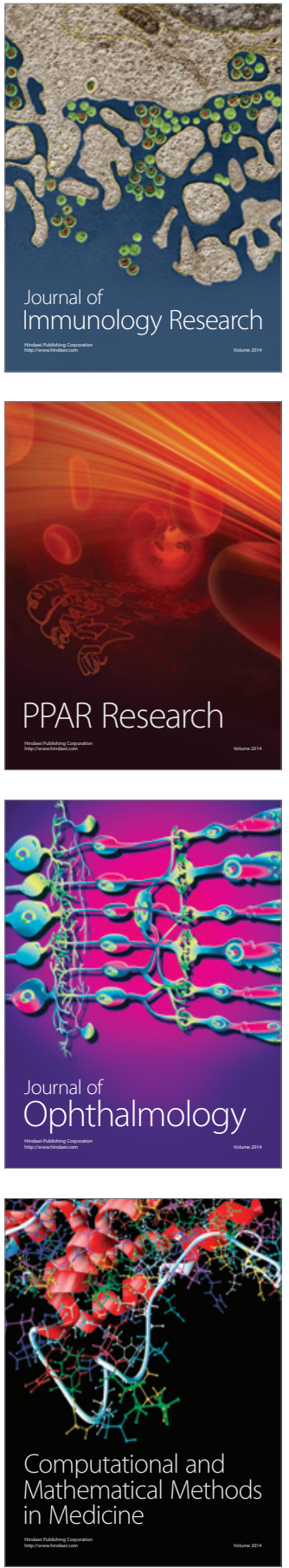

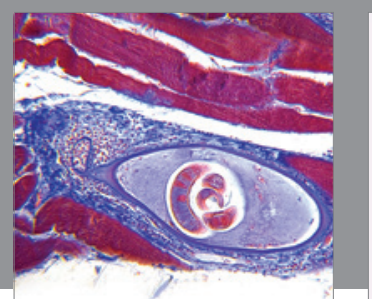

Gastroenterology Research and Practice

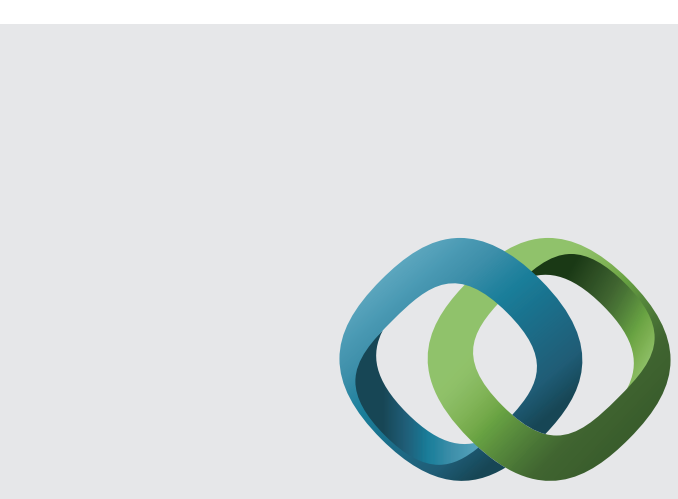

\section{Hindawi}

Submit your manuscripts at

http://www.hindawi.com
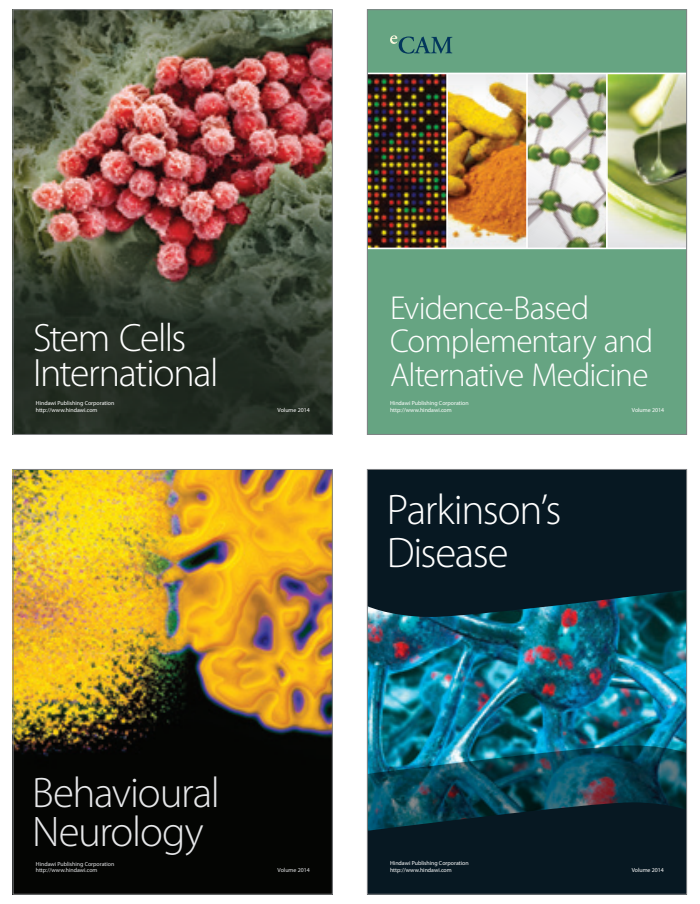
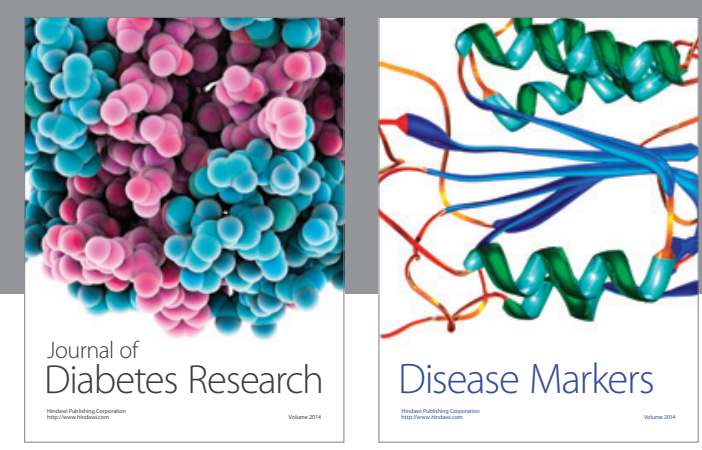

Disease Markers
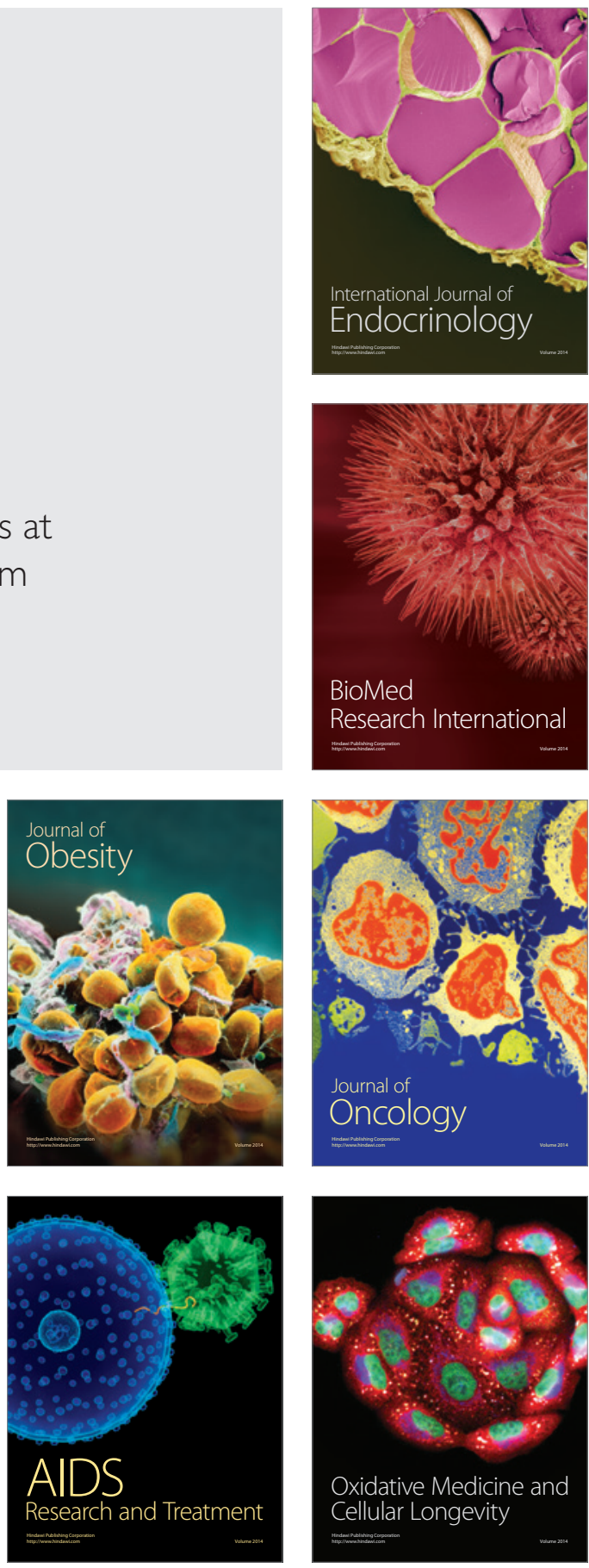